\title{
Effect of Brazilian green propolis in patients with type 2 diabetes: A double-blind randomized placebo-controlled study
}

\author{
TAKUYA FUKUDA $^{1}$, MICHIAKI FUKUI $^{1 *}$, MUHEI TANAKA $^{1}$, TAKAFUMI SENMARU ${ }^{1}$, \\ HIROYA IWASE ${ }^{1}$, MASAHIRO YAMAZAKI ${ }^{1}$, WATARU AOI ${ }^{2}$, TOSHIO INUI ${ }^{3,4}$, \\ NAOTO NAKAMURA ${ }^{1}$ and YOSHINORI MARUNAKA ${ }^{3,5^{*}}$
}

\begin{abstract}
${ }^{1}$ Department of Endocrinology and Metabolism, Graduate School of Medical Science, Kyoto Prefectural University of Medicine, Kyoto 602-8566; ${ }^{2}$ Laboratory of Health Science, Graduate School of Life and Environmental Sciences, Kyoto Prefectural University, Kyoto 606-8522; ${ }^{3}$ Departments of Molecular Cell Physiology and Bio-Ionomics, Graduate School of Medical Science, Kyoto Prefectural University of Medicine, Kyoto 602-8566; ${ }^{4}$ Saisei Mirai Clinics, Moriguchi 570-0012; 5 Japan Institute for Food Education and Health, St. Agnes' University, Kyoto 602-8013, Japan
\end{abstract}

Received February 3, 2015; Accepted February 6, 2015

DOI: $10.3892 /$ br.2015.436

\begin{abstract}
Propolis contains a variety of chemical compounds, including polyphenols, flavonoids, phenolic aldehydes, amino acids and vitamins, and presents numerous biological and pharmacological properties. The aim of the present study was to evaluate the effect of propolis on blood examination data in patients with type 2 diabetes. In the double-blind, 8 -week randomized controlled study, 80 patients with type 2 diabetes were enrolled. Patients were randomly assigned to receive Brazilian green propolis (226.8 mg/day for 8 weeks) $(n=41)$ or the placebo $(n=39)$. The primary endpoint was to detect changes in blood examination data associated with metabolic disorders in patients suffering from diabetes mellitus, including the homeostasis model assessment of insulin resistance (HOMA-IR), uric acid and estimated glomerular filtration rate (eGFR) from baseline to the end of this study. The value of HOMA-IR was not significantly changed by the 8-week administration of propolis or placebo from the baseline data. Values of blood uric acid and eGFR in patients taking the placebo became worse at 8 weeks compared to the baseline, whereas this did not occur
\end{abstract}

Correspondence to: Dr Michiaki Fukui, Department of Endocrinology and Metabolism, Graduate School of Medical Science, Kyoto Prefectural University of Medicine, 465 Kajii-cho, Kawaramachi-Hirokoji, Kamigyo-ku, Kyoto 602-8566, Japan E-mail: sayarinapm@hotmail.com

Professor Yoshinori Marunaka, Department of Molecular Cell Physiology and Bio-Ionomics, Graduate School of Medical Science, Kyoto Prefectural University of Medicine, 465 Kajii-cho, Kawaramachi-Hirokoji, Kamigyo-ku, Kyoto 602-8566, Japan E-mail: marunaka@koto.kpu-m.ac.jp

*Contributed equally

Key words: propolis, diabetes, type 2 diabetes, randomized control study in patients consuming Brazilian green propolis. However, HOMA-IR was not improved by propolis intake. A randomized, controlled 8-week trial suggests that Brazilian green propolis ( $226.8 \mathrm{mg} /$ day) prevents patients with type 2 diabetes from developing worse blood uric acid and eGFR.

\section{Introduction}

Diabetes is a syndrome presenting with chronic hyperglycemia arising from insufficiency of insulin activity (1). Insulin resistance is defined as a decreased response of the peripheral tissues to insulin activity. Individuals with insulin resistance are predisposed to developing type 2 diabetes mellitus. Previous studies have revealed that the plasma concentration of inflammatory mediators, such as tumor necrosis factor- $\alpha$ (TNF- $\alpha$ ), interleukin-6 (IL-6) and high sensitivity C-reactive protein (hsCRP) is increased in the insulin resistant states of obesity and type 2 diabetes (2-4).

Propolis is a resinous material collected by the Apis mellifera bee from leaf buds and cracks in the bark of various plants. Propolis contains a variety of chemical compounds, including polyphenols, flavonoids, amino acids, vitamins (5) and caffeic acid phenethyl ester (6). Propolis presents numerous biological and pharmacological properties, such as immunomodulatory, antitumor, anti-inflammatory and antioxidant activity (7). In previous years, a number of studies have identified that propolis has hypoglycemic effects in animal models with type 2 diabetes (8-10). To the best of our knowledge, however, there have been no studies regarding these effects in human.

The aim of the present paper was to evaluate the effect of the Brazilian green propolis extract on glucose metabolism, renal function, lipid metabolism and inflammatory cytokines in patients with type 2 diabetes.

\section{Materials and methods}

Enrolled participants. Patients with type 2 diabetes were screened and enrolled if they were aged 35-80 years and 
received treatment with diet and exercise, oral hypoglycemic agents or glucagon-like peptide-1 receptor agonists at the Kyoto Prefectural University of Medicine (Kyoto, Japan).

All the patients provided details of their demographics, medical history and medication usage. Body mass index was calculated as weight in kilograms divided by height in meters squared. Type 2 diabetes was diagnosed according to the Report of the Expert Committee on the Diagnosis and Classification of Diabetes Mellitus (11). Nephropathy was graded as follows: Normoalbuminuria, urinary albumin excretion (UAE) $<30 \mathrm{mg} / \mathrm{g}$ of creatinine (Cr); microalbuminuria, 30-300 mg/g Cr; and macroalbumiuria, $>300 \mathrm{mg} / \mathrm{g} \mathrm{Cr}$.

Thepatients treated with insulinwereexcluded.In addition, the following patients were also excluded: Severe renal dysfunction [estimated glomerular filtration rate (eGFR) $<30 \mathrm{ml} / \mathrm{min} / 1.73 \mathrm{~m}^{2}$ ] and/or hepatic dysfunction (aspartate aminotransferase $>100 \mathrm{U} / 1$ or alanine aminotransferase $>100 \mathrm{U} / \mathrm{l}$ ), as well as pregnant females. The study was examined and approved by the Institutional Review Board (IRB) and was subsequently implemented in accordance with Good Clinical Practice. The investigator or sub-investigator informed each candidate patient of the study design using the leaflet and consent form authorized by the IRB prior to enrolling the patient in the study, and the patient consent was obtained in writing.

Study design and methods. The present study was a randomized, double-blind study. For allocation of the participants, the numbered container method was used. The placebo served as a reference drug for comparison.

The propolis group received Brazilian green propolis (226.8 $\mathrm{mg}, 8.4 \mathrm{kcal} / \mathrm{day}$ ), whereas the placebo group received tablets containing safflower oil, wheat germ oil and perilla oil $(8.4 \mathrm{kcal} / \mathrm{day})$. Brazilian green propolis was provided by the Yamada Bee Company, Inc. (Okayama, Japan). In each group, oral medication was administered once a day for 8 weeks. The diabetic diet and exercise regimen at baseline was continued, and was not changed during the study.

The primary outcome was the change in homeostasis model assessment of insulin resistance (HOMA-IR) at the end of the study. Secondary outcomes were the changes in fasting plasma glucose, glycated hemoglobin $\left(\mathrm{HbA}_{1 \mathrm{c}}\right)$, serum insulin, total cholesterol, high-density lipoprotein, low-density lipoprotein, triglyceride, remnant-like particle lipoprotein cholesterol, uric acid, eGFR, TNF- $\alpha$, IL-6, hsCRP, urine $\mathrm{pH}$ and UAE.

Biochemical analysis. Laboratory tests (hematology, biochemistry and urinalysis) were carried out before and 8 weeks after the start of taking tablets. Fasting blood and urine samples were obtained in the morning. The data of the laboratory tests were measured at a central laboratory institute at the Kyoto Prefectural University of Medicine. Fasting plasma glucose and insulin levels were used to calculate HOMA-IR, as previously reported (12). $\mathrm{HbA}_{\mathrm{lc}}$ was assayed using high-performance liquid chromatography and was expressed as a National Glycohemoglobin Standardization Program unit. eGFR was calculated using the Japanese Society of Nephrology equation: eGFR $=194 \mathrm{x} \mathrm{Cr}^{-1.094} \mathrm{x}$ age $-0.287\left(\mathrm{ml} / \mathrm{min} / 1.73 \mathrm{~m}^{2}\right)$ for males, and for females the eGFR was multiplied by a correction factor of 0.739 (13). Urinary albumin and $\mathrm{Cr}$ concentrations were determined using early

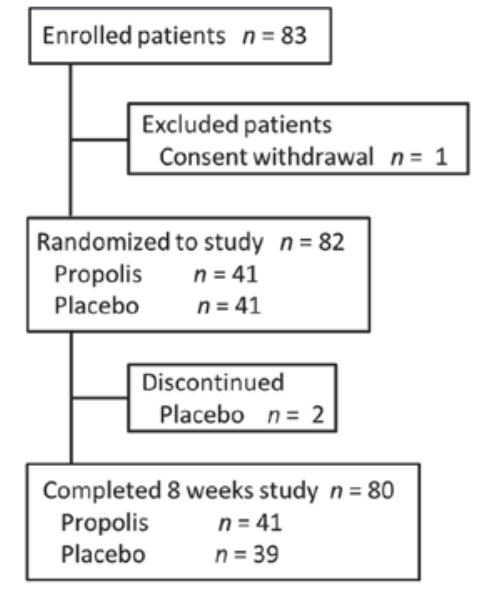

Figure 1. Enrollment and outcomes of the study.

morning spot urine. UAE was measured with an immunoturbidimetric assay.

Statistical analysis. With a study sample of 82 patients (41 in each group), the study was estimated to have $80 \%$ power to detect a clinically important difference in the absolute difference in HOMA-IR of $\sim 1$ between the two groups, assuming a standard deviation (SD) of 1.4 and a two-sided type one error rate of $5 \%$.

The mean values are expressed as the mean $\pm \mathrm{SD}$. All the statistical tests were two-tailed and $\mathrm{P}<0.05$ was considered to indicate a statistically significant difference. As triglycerides, hsCRP and UAE showed skewed distributions, the data were normalized by logarithmic transformation for further statistical analysis. The differences in categorical variables between the two groups were evaluated using Fisher's exact test. Continuous variables were compared using a Student's t-test and a Mann-Whitney $U$ test if appropriate for non-normally distributed data. All the statistical analyses were carried out using the JMP software, version 10.0 (SAS Institute Inc., Cary, NC, USA).

\section{Results}

Demographic information of patients. Between June and August 2012, a total of 82 patients were randomized to administration with propolis $(\mathrm{n}=41)$ or placebo $(\mathrm{n}=41)$ and 80 patients were finally included in the full analysis set: 41 for the propolis group and 39 for the placebo group (Fig. 1). Two patients in the placebo group discontinued due to the onset of acute myocardial infarction and cellulitis, respectively. Demographic and baseline characteristics of the 80 randomized patients are summarized in Table I. The mean age, proportion of males and proportion of diabetic microangiopathic complications were similar between the propolis and the placebo groups. There were no significant differences in the use of sulfonylureas, dipeptidyl peptidase-4 inhibitors, glucagon-like peptide-1 receptor agonists, pioglitazones and biguanides at study entry between the two groups. Furthermore, the mean systolic/diastolic blood pressure and all the biochemical data in the baseline were similar between the two groups (Table I). The two groups differed significantly in the duration of diabetes only $(\mathrm{P}<0.05)$. 
Table I. Clinical and laboratory characteristics of patients.

\begin{tabular}{|c|c|c|c|}
\hline Variables & Propolis $(n=41)$ & Placebo $(n=39)$ & P-value \\
\hline Age, years & $63.7 \pm 9.3$ & $62.9 \pm 7.8$ & 0.69 \\
\hline Gender, male/female & $27 / 14$ & $19 / 20$ & 0.12 \\
\hline Body weight, kg & $62.8 \pm 15.0$ & $65.1 \pm 9.9$ & 0.43 \\
\hline BMI, $\mathrm{kg} / \mathrm{m}^{2}$ & $25.0 \pm 4.8$ & $25.0 \pm 3.5$ & 0.98 \\
\hline Duration of diabetes, years & $13.7 \pm 10.3$ & $9.8 \pm 6.2$ & $<0.05$ \\
\hline Retinopathy, NDR/SDR/PDR & $31 / 5 / 5$ & $30 / 3 / 6$ & 0.76 \\
\hline Nephropathy, normo/micro/macroalbuminuria & $29 / 9 / 3$ & $29 / 8 / 2$ & 0.95 \\
\hline Neuropathy, -/+ & $26 / 15$ & $25 / 14$ & 0.95 \\
\hline Hypertension, -/+ & $18 / 23$ & $11 / 28$ & 0.14 \\
\hline Hyperlipidemia, -/+ & $22 / 19$ & $18 / 21$ & 0.50 \\
\hline Sulfonylurea, -/+ & $17 / 24$ & $20 / 19$ & 0.38 \\
\hline Dipeptidyl peptidase-4 inhibitor, -/+ & $21 / 20$ & $20 / 19$ & 1.00 \\
\hline Glucagon like peptide-1 receptor agonist, -/+ & $37 / 4$ & $35 / 4$ & 0.94 \\
\hline Pioglitazone, -/+ & $37 / 4$ & $35 / 4$ & 0.94 \\
\hline Biguanide, -/+ & $19 / 22$ & $20 / 19$ & 0.75 \\
\hline Systolic blood pressure, $\mathrm{mmHg}$ & $124.8 \pm 15.5$ & $125.4 \pm 14.6$ & 0.88 \\
\hline Diastolic blood pressure, $\mathrm{mmHg}$ & $71.0 \pm 12.9$ & $71.1 \pm 10.9$ & 0.97 \\
\hline Fasting plasma glucose, mg/dl & $133.8 \pm 25.3$ & $138.8 \pm 33.6$ & 0.46 \\
\hline Hemoglobin $\mathrm{A}_{1 \mathrm{c}}, \%$ & $7.09 \pm 0.79$ & $7.21 \pm 0.85$ & 0.52 \\
\hline Insulin, $\mu \mathrm{IU} / \mathrm{ml}$ & $6.94 \pm 3.75$ & $7.74 \pm 3.42$ & 0.32 \\
\hline HOMA-IR & $2.34 \pm 1.36$ & $2.64 \pm 1.39$ & 0.33 \\
\hline AST, IU/1 & $24.4 \pm 10.3$ & $24.1 \pm 7.5$ & 0.88 \\
\hline ALT, IU/1 & $23.8 \pm 17.1$ & $26.7 \pm 12.0$ & 0.39 \\
\hline Uric acid, mg/dl & $5.51 \pm 1.23$ & $5.23 \pm 1.30$ & 0.33 \\
\hline Serum Cr, mg/dl & $0.73 \pm 0.26$ & $0.75 \pm 0.22$ & 0.69 \\
\hline $\mathrm{eGFR}, \mathrm{ml} / \mathrm{min} / 1.73 \mathrm{~m}^{2}$ & $75.5 \pm 21.7$ & $74.9 \pm 17.3$ & 0.90 \\
\hline Total cholesterol, mg/dl & $180.4 \pm 29.4$ & $181.6 \pm 34.9$ & 0.87 \\
\hline HDL cholesterol, mg/dl & $59.7 \pm 15.2$ & $54.5 \pm 16.4$ & 0.14 \\
\hline LDL cholesterol, mg/dl & $108.5 \pm 24.2$ & $114.6 \pm 29.1$ & 0.30 \\
\hline Log Triglycerides, mg/dl & $4.70 \pm 0.53$ & $4.78 \pm 0.36$ & 0.44 \\
\hline RLP cholesterol, mg/dl & $4.79 \pm 2.90$ & $4.77 \pm 2.49$ & 0.97 \\
\hline TNF- $\alpha, n g / m l$ & $1.4(1.2-1.9)$ & $1.4(1.2-1.7)$ & 0.32 \\
\hline IL-6, pg/ml & $2.0(1.3-2.8)$ & $1.4(1.0-2.3)$ & 0.69 \\
\hline Log hsCRP, mg/l & $6.38 \pm 1.28$ & $6.52 \pm 1.12$ & 0.60 \\
\hline Urine, $\mathrm{pH}$ & $6.00 \pm 0.63$ & $5.95 \pm 0.57$ & 0.69 \\
\hline Log UAE, mg/g Cr & $3.07 \pm 1.54$ & $2.67 \pm 1.43$ & 0.24 \\
\hline
\end{tabular}

Data are shown as the mean \pm standard deviation, median (interquartile range) or number of patients. BMI, body mass index; NDR, no diabetic retinopathy; SDR, simple diabetic retinopathy; PDR, proliferative diabetic retinopathy; HOMA-IR, homeostasis model assessment of insulin resistance; AST, aspartate aminotransferase; ALT, alanine aminotransferase; Cr, creatinine; eGFR, estimated glomerular filtration rate; HDL, high-density lipoprotein; LDL, low-density lipoprotein; RLP, remnant-like particle; TNF- $\alpha$, tumor necrosis-factor $\alpha$; IL-6, interleukin-6; hsCRP, high sensitivity C-reactive protein; UAE, urinary albumin excretion.

Efficacy. In the control group, HOMA-IR changed from $2.64 \pm 1.39$ at baseline to $2.73 \pm 1.52$ at 8 weeks after administration of the placebo. In the propolis group, HOMA-IR changed from $2.34 \pm 1.36$ at baseline to $2.33 \pm 1.56$ at 8 weeks after administration. The mean difference of HOMA-IR, which was a primary outcome between the baseline data and the data at 8 weeks after administration, was not significant between the two groups $(\mathrm{P}=0.62)$ (Table II). Furthermore, each group showed no significant change in HOMA-IR
8 weeks after the intake of propolis or placebo compared to the baseline.

All the parameters of glucose metabolism, renal function, lipid metabolism and inflammatory cytokines, which were secondary outcomes between baseline data and data at 8 weeks after administration, between the two groups did not have significant differences (Table II). However, it is notable that the concentration of uric acid in the blood of patients taking the placebo significantly increased 8 weeks later compared 
Table II. Changes in the parameters during 8 weeks of placebo or propolis administration.

\begin{tabular}{|c|c|c|c|c|c|c|}
\hline \multirow[b]{2}{*}{ Variables } & \multicolumn{2}{|c|}{ Placebo (n=39) } & \multicolumn{2}{|c|}{ Propolis $(n=41)$} & \multirow[b]{2}{*}{ Difference $(95 \% \mathrm{CI})$} & \multirow[b]{2}{*}{ P-value ${ }^{a}$} \\
\hline & Baseline & After 8 weeks & Baseline & After 8 weeks & & \\
\hline \multicolumn{7}{|l|}{ Primary outcome } \\
\hline HOMA-IR & $2.64 \pm 1.39$ & $2.73 \pm 1.52$ & $2.34 \pm 1.36$ & $2.33 \pm 1.56$ & $-0.10(-0.51$ to 0.31$)$ & 0.62 \\
\hline \multicolumn{7}{|l|}{ Secondary outcome } \\
\hline Fasting plasma glucose, $\mathrm{mg} / \mathrm{dl}$ & $138.8 \pm 33.6$ & $136.8 \pm 27.8$ & $133.8 \pm 25.3$ & $130.2 \pm 28.1$ & $-1.63(-11.81$ to 5.11$)$ & 0.75 \\
\hline Hemoglobin A1c, \% & $7.21 \pm 0.85$ & $7.23 \pm 0.89$ & $7.09 \pm 0.79$ & $7.08 \pm 0.79$ & $-0.03(-0.13$ to 0.19$)$ & 0.69 \\
\hline Insulin, $\mu \mathrm{IU} / \mathrm{ml}$ & $7.74 \pm 3.42$ & $8.15 \pm 4.50$ & $6.94 \pm 3.75$ & $6.92 \pm 3.82$ & $-0.43(-1.55$ to 0.69$)$ & 0.45 \\
\hline Uric acid, mg/dl & $5.23 \pm 1.30$ & $5.44 \pm 1.44^{\mathrm{b}}$ & $5.51 \pm 1.23$ & $5.48 \pm 1.38$ & $-0.23(-0.52$ to 0.06$)$ & 0.11 \\
\hline $\mathrm{eGFR}, \mathrm{ml} / \mathrm{min} / 1.73 \mathrm{~m}^{2}$ & $74.9 \pm 17.3$ & $72.2 \pm 18.4^{\mathrm{b}}$ & $75.5 \pm 21.7$ & $74.5 \pm 19.7$ & $1.74(-1.99$ to 5.48$)$ & 0.36 \\
\hline Total cholesterol, mg/dl & $181.6 \pm 34.9$ & $180.7 \pm 32.7$ & $180.4 \pm 29.4$ & $177.7 \pm 32.5$ & $-1.91(-8.31$ to 4.49$)$ & 0.55 \\
\hline HDL cholesterol, mg/dl & $54.5 \pm 16.4$ & $54.4 \pm 16.5$ & $59.7 \pm 15.2$ & $59.3 \pm 15.8$ & $-0.39(-2.49$ to 1.71$)$ & 0.71 \\
\hline LDL cholesterol, mg/dl & $114.6 \pm 29.1$ & $115.0 \pm 27.0$ & $108.5 \pm 24.2$ & $107.6 \pm 26.7$ & $-1.16(-6.72$ to 4.39$)$ & 0.68 \\
\hline Log triglycerides, mg/dl & $4.78 \pm 0.36$ & $4.75 \pm 0.38$ & $4.70 \pm 0.53$ & $4.63 \pm 0.48$ & $-0.04(-0.16$ to 0.08$)$ & 0.51 \\
\hline RLP cholesterol, mg/dl & $4.77 \pm 2.49$ & $4.09 \pm 2.10$ & $4.79 \pm 2.90$ & $4.83 \pm 2.68$ & $0.76(-0.28$ to 1.80$)$ & 0.15 \\
\hline $\mathrm{TNF}-\alpha, \mathrm{ng} / \mathrm{ml}$ & $1.4(1.2-1.7)$ & $1.5(1.4-1.9)$ & $1.4(1.2-1.9)$ & $1.4(1.2-1.8)$ & $-0.15(-0.66$ to 0.36$)$ & 0.56 \\
\hline IL-6, pg/ml & $1.4(1.0-2.3)$ & $1.6(1.1-2.2)$ & $2.0(1.3-2.8)$ & $1.6(1.2-2.6)$ & $-0.51(-1.61$ to 0.59$)$ & 0.36 \\
\hline Log hsCRP, mg/l & $6.38 \pm 1.28$ & $6.26 \pm 1.07$ & $6.52 \pm 1.12$ & $6.45 \pm 1.22$ & $0.05(-0.36$ to 0.47$)$ & 0.81 \\
\hline Urine, $\mathrm{pH}$ & $5.95 \pm 0.57$ & $5.95 \pm 0.74$ & $6.00 \pm 0.63$ & $5.93 \pm 0.76$ & $-0.07(-0.32$ to 0.17$)$ & 0.56 \\
\hline Log UAE, mg/g Cr & $2.67 \pm 1.43$ & $2.65 \pm 1.04$ & $3.07 \pm 1.54$ & $2.97 \pm 1.50$ & $-0.07(-0.35$ to 0.21$)$ & 0.62 \\
\hline
\end{tabular}

${ }^{\mathrm{a} C}$ Comparison of the change between placebo and propolis from baseline at 8 weeks; ${ }^{\mathrm{b}} \mathrm{P}<0.05$ for baseline versus after 8 weeks. Data are mean \pm standard deviation. CI, confidence interval; HOMA-IR, homeostasis model assessment of insulin resistance; eGFR, estimated glomerular filtration rate; HDL, high-density lipoprotein; LDL, low-density lipoprotein; RLP, remnant-like particle; TNF- $\alpha$, tumor necrosis-factor $\alpha$; IL-6, interleukin-6; hsCRP, high sensitivity C-reactive protein; UAE, urinary albumin excretion; $\mathrm{Cr}$, creatinine.

to the baseline $(\mathrm{P}<0.05$; Table II), while in patients taking propolis it was maintained at a level similar to the baseline but did not significantly increase 8 weeks later $(\mathrm{P}=0.80$; Table II). Furthermore, eGFR was decreased in patients taking placebo 8 weeks later compared to the baseline $(\mathrm{P}<0.01$; Table II), while eGFR in patients taking propolis was maintained at a similar level to the baseline without any decrease 8 weeks later $(\mathrm{P}=0.52$; Table II). Although TNF- $\alpha$ did not significantly increase in either group, patients taking the placebo showed a tendency to increase TNF- $\alpha(\mathrm{P}=0.08$; Table II), the value of which in patients taking propolis was stable $(\mathrm{P}=0.98$; Table II). No reports on side effects, including allergy, were noted in patients who finished the protocol.

\section{Discussion}

The present study examined the efficacy of Brazilian green propolis compared to the placebo for 8 weeks in Japanese patients with type 2 diabetes. To the best of our knowledge, this is the first double-blind randomized placebo-controlled study to investigate the effectiveness of propolis in patients with type 2 diabetes. In the study, there were no evident differences between the propolis and the placebo groups in the changes of HOMA-IR, $\mathrm{HbA}_{1 \mathrm{c}}$, fasting blood glucose or serum insulin level, so therefore, intake of $226.8 \mathrm{mg}$ propolis/day for 8 weeks did not improve glucose metabolism in the patients with type 2 diabetes. However, as shown in Table II, the concentration of uric acid in the blood of patients taking propolis for 8 weeks was maintained at a level identical to the baseline without any significant increase $(\mathrm{P}=0.80$; Table II), while for the patients taking the placebo, the concentration significantly elevated 8 weeks later $(\mathrm{P}<0.05$; Table II). Furthermore, intake of $226.8 \mathrm{mg}$ propolis/day did not improve eGFR, but maintained eGFR at the baseline without any decrease for 8 weeks ( $\mathrm{P}=0.52$; Table II). By contrast, eGFR of diabetic patients taking the placebo decreased 8 weeks later compared to the baseline $(\mathrm{P}<0.01$; Table II). Furthermore, daily intake of propolis maintained TNF- $\alpha$ at a stable value for 8 weeks without any significant elevation ( $\mathrm{P}=0.98$; Table II), while diabetic patients taking the placebo showed a tendency to increase TNF- $\alpha(\mathrm{P}=0.08$; Table II). These observations suggest that daily intake of $226.8 \mathrm{mg}$ propolis for 8 weeks prevents diabetic patients from developing a worse renal glomerular filtrating function and elevation of blood uric acid, and may have an anti-inflammatory action.

The biological action of propolis originates from its active constituents, which differ in type and amount in the various types of propolis (14). Brazilian propolis represents $10-15 \%$ of the worldwide production and Brazil is the third world producer behind Russia and China (15). Among the types produced in Brazil, green propolis prevails and gains preference in the world propolis market. In the present study, the high quality Brazilian green propolis was used. Although toxic data for propolis are limited, various allergens have been 
isolated from propolis; such as 3-methyl-2-butenyl caffeate, phenylethyl caffeate, benzyl caffeate, geranyl caffeate, benzyl alcohol benzyl cinnammate, methyl cinnammate, ferulic acid and tectochrysin (16). Therefore, allergic reactions were of concern in the present study; however, no patient in the propolis group suffered from allergic reactions.

Multifold pathways, including increased polyol pathway flux, overactivity of the hexosamine pathway, increased formation of advanced glycation end-products and activation of protein kinase $\mathrm{C}$ isoforms, are involved in diabetic complications (17). Increased reactive oxygen species inducing hyperglycemia-activated electron-transport chain in mitochondria are believed to be a main underlying mechanism linking all of these factors, and oxidative stress is possibly involved in the progression of pancreatic $\beta$-cell dysfunction (18). Propolis has a strong antioxidative activity and is confirmed to inhibit the increase of the malonaldehyde (MDA) level and improve antioxidase activity in the animal model and patients $(19,20)$. Previous studies have reported that propolis can prevent oxidative stress-induced tissue damage by decreasing the overproduction of MDA and superoxide anion, and by restoring the respiratory control ration in mitochondrial tissue $(21,22)$. Therefore, propolis may improve glucose metabolism by an attenuation of mitochondrial oxidative stress.

In addition, extracellular $\mathrm{pH}$ plays an important role in glucose metabolism. In a rat skeletal muscle-derived cell line, L6 cell, the phosphorylation level of the insulin receptor and Akt is significantly diminished in low $\mathrm{pH}$ media, and binding of insulin to its receptor on the plasma membrane is reduced by lowering the extracellular $\mathrm{pH}$, while the expression of insulin receptors on the plasma membrane is not affected. As a result, insulin-stimulated 2-deoxyglucose uptake in L6 cells is diminished in low pH media (23). An ex vivo study by Yamauchi et al (24) reported that insulin-mediated 2-deoxy-D-glucose uptake by rat soleus muscle is inhibited by a reduction in the $\mathrm{pH}$ of the medium from 7.4 to 6.8. Furthermore, Aoi et al (25) have reported that a propolis-contained diet improved, by increasing, the $\mathrm{pH}$ of ascites and metabolic tissues compared to the normal diet and improved glucose metabolism in Otsuka Long-Evans Tokushima Fatty rats, whose $\mathrm{pH}$ in various tissues was lower compared to normal rats (25-27). Therefore, propolis may improve insulin sensitivity by an increase of extracellular $\mathrm{pH}$.

In the present study, at least two limitations should be noted. First, the trial may have been too short to observe the change of glucose metabolism. Propolis may require a longer duration to improve glucose metabolism in humans, so administration of propolis for 8 weeks appears to be unlikely to elicit significant improvements in $\mathrm{HbA}_{1 \mathrm{c}}$. Second, the dose of propolis may not have been sufficient. Numerous studies report the efficacy of propolis on diabetes; however, the majority are animal experiments and administered doses of propolis were extremely high (such as 50-300 mg/kg of the body weight) (8-10,28-30). Therefore, if a higher dose of propolis was administered to patients, the effect of propolis on glucose metabolism may take effect.

In conclusion, $226.8 \mathrm{mg} /$ day of Brazilian green propolis for 8 weeks prevented the actions of hyperuricemia and dysfunction of renal glomerular filtrating function that commonly develop in patients suffering from diabetes mellitus. Therefore, further clinical studies should be continued to verify whether much higher doses and/or longer administration of Brazilian green propolis are useful in the prevention and care of diabetes mellitus.

\section{Acknowledgements}

The present study was supported by Grants-in-Aid, mainly from the Yamada Research Grant.

\section{References}

1. Defronzo RA: Banting Lecture. From the triumvirate to the ominous octet: A new paradigm for the treatment of type 2 diabetes mellitus. Diabetes 58: 773-795, 2009.

2. Hotamisligil GS, Shargill NS and Spiegelman BM: Adipose expression of tumor necrosis factor-alpha: Direct role in obesity-linked insulin resistance. Science 259: 87-91, 1993.

3. Pickup JC, Mattock MB, Chusney GD and Burt D: NIDDM as a disease of the innate immune system: Association of acute-phase reactants and interleukin-6 with metabolic syndrome $\mathrm{X}$. Diabetologia 40: 1286-1292, 1997.

4. Kang ES, Kim HJ, Ahn CW, Park CW, Cha BS, Lim SK, Kim KR and Lee HC: Relationship of serum high sensitivity C-reactive protein to metabolic syndrome and microvascular complications in type 2 diabetes. Diabetes Res Clin Pract 69: 151-159, 2005

5. Khalil ML: Biological activity of bee propolis in health and disease. Asian Pac J Cancer Prev 7: 22-31, 2006.

6. Grunberger D, Banerjee R, Eisinger K, Oltz EM, Efros L, Caldwell M, Estevez V and Nakanishi K: Preferential cytotoxicity on tumor cells by caffeic acid phenethyl ester isolated from propolis. Experientia 44: 230-232, 1988.

7. Banskota AH, Tezuka Y and Kadota S: Recent progress in pharmacological research of propolis. Phytother Res 15: 561-571, 2001.

8. Al-Hariri MT: Propolis and its direct and indirect hypoglycemic effect. J Fam Community Med 18: 152-154, 2011.

9. Matsui T, Ebuchi S, Fujise T, Abesundara KJ, Doi S, Yamada H and Matsumoto K: Strong antihyperglycemic effects of water-soluble fraction of Brazilian propolis and its bioactive constituent, 3,4,5-tri-O-caffeoylquinic acid. Biol Pharm Bull 27: 1797-1803, 2004.

10. Zhu W, Chen M, Shou Q, Li Y and Hu F: Biological activities of chinese propolis and brazilian propolis on streptozotocin-induced type 1 diabetes mellitus in rats. Evid Based Complement Alternat Med 2011: 468529, 2011.

11. Expert Committee on the Diagnosis and Classification of Diabetes Mellitus: Report of the expert committee on the diagnosis and classification of diabetes mellitus. Diabetes Care 26 (Suppl 1): S5-S20, 2003.

12. Matthews DR, Hosker JP, Rudenski AS, Naylor BA, Treacher DF and Turner RC: Homeostasis model assessment: Insulin resistance and beta-cell function from fasting plasma glucose and insulin concentrations in man. Diabetologia 28: 412-419, 1985.

13. Matsuo S, Imai E, Horio M, Yasuda Y, Tomita K, Nitta K, Yamagata K, Tomino Y, Yokoyama $\mathrm{H}$ and Hishida A; Collaborators developing the Japanese equation for estimated GFR: Revised equations for estimated GFR from serum creatinine in Japan. Am J Kidney Dis 53: 982-992, 2009.

14. Bankova V: Chemical diversity of propolis and the problem of standardization. J Ethnopharmacol 100: 114-117, 2005.

15. Paviani LC, Dariva C, Marcucci MC and Cabral FA: Super critical carbon dioxide selectivity to fractionate phenolic compounds from the dry ethanolic extract of propolis. J Food Process Eng 33: 15-27, 2010.

16. Gardana $\mathrm{C}$ and Simonetti P: Evaluation of allergens in propolis by ultra-performance liquid chromatography/tandem mass spectrometry. Rapid Commun Mass Spectrom 25: 1675-1682, 2011.

17. Giacco F and Brownlee M: Oxidative stress and diabetic complications. Circ Res 107: 1058-1070, 2010.

18. Kajimoto $\mathrm{Y}$ and Kaneto $\mathrm{H}$ : Role of oxidative stress in pancreatic beta-cell dysfunction. Ann N Y Acad Sci 1011: 168-176, 2004.

19. Jasprica I, Mornar A, Debeljak Z, et al: In vivo study of propolis supplementation effects on antioxidative status and red blood cells. J Ethnopharmacol 110: 548-554, 2007. 
20. Kanbur M, Eraslan G and Silici S: Antioxidant effect of propolis against exposure to propetamphos in rats. Ecotoxicol Environ Saf 72: 909-915, 2009.

21. Majiene D, Trumbeckaite S, Savickas A and Toleikis A: Influence of propolis water solution on heart mitochondrial function. J Pharm Pharmacol 58: 709-713, 2006.

22. Alyane M, Kebsa LBW, Boussenane H, Rouibah H and Lahouel M: Cardioprotective effects and mechanism of action of polyphenols extracted from propolis against doxorubicin toxicity. Pak J Pharm Sci 21: 201-209, 2008.

23. Hayata H, Miyazaki H, Niisato N, Yokoyama N and Marunaka Y: Lowered extracellular $\mathrm{pH}$ is involved in the pathogenesis of skeletal muscle insulin resistance. Biochem Biophys Res Commun 445: 170-174, 2014.

24. Yamauchi T, Sekiya K, Okuda $\mathrm{H}$ and Kimura S: Role of $\mathrm{Na}^{+} / \mathrm{H}^{+}$ exchanger in insulin-stimulated glucose uptake into skeletal muscle. Agressologie 32: 115-120, 1991.

25. Aoi W,Hosogi S, Niisato N, et al: Improvement of insulin resistance, blood pressure and interstitial $\mathrm{pH}$ in early developmental stage of insulin resistance in OLETF rats by intake of propolis extracts. Biochem Biophys Res Commun 432: 650-653, 2013.
26. Marunaka Y, Yoshimoto K, Aoi W, Hosogi S and Ikegaya H: Low $\mathrm{pH}$ of interstitial fluid around hippocampus of the brain in diabetic OLETF rats. Mol Cell Ther 2: 6, 2014

27. Aoi W and Marunaka Y: Importance of $\mathrm{pH}$ homeostasis in metabolic health and diseases: Crucial role of membrane proton transport. Biomed Res Int 2014: 598986, 2014.

28. El-Sayed SM, Abo-Salem OM, Aly HA and Mansour AM: Potential antidiabetic and hypolipidemic effects of propolis extract in streptozotocin-induced diabetic rats. Pak J Pharm Sci 22: 168-174, 2009.

29. Kang L-J, Lee HB, Bae H-J and Lee SG: Antidiabetic effect of propolis: Reduction of expression of glucose-6-phosphatase through inhibition of Y279 and Y216 autophosphorylation of GSK-3 $\alpha / \beta$ in HepG2 cells. Phytother Res 24: 1554-1561, 2010.

30. Li Y, Chen M, Xuan $\mathrm{H}$ and $\mathrm{Hu} \mathrm{F}$ : Effects of encapsulated propolis on blood glycemic control, lipid metabolism, and insulin resistance in type 2 diabetes mellitus rats. Evid Based Complement Alternat Med 2012: 981896, 2012. 